\title{
Nuevas reflexiones en torno al cuaderno de Antonio Primo (1761-1764), pensionado en Roma de la Real Academia de Bellas Artes de San Fernando de Madrid
}

\author{
New reflections on the Antonio Primo's sketchbook \\ (1761-1764), a budding artist of the Real Academia de \\ Bellas Artes de San Fernando of Madrid in Rome
}

Raquel GALLEGO GARCÍA

Universitat de Barcelona

Recibido: 29-VIII-2015

Aceptado: 28-III-2016

Resumen: Antonio Primo empleó un cuaderno durante parte de su estancia en Roma (1761-1764) en el que bosquejó dibujos de aquellas obras que suscitaron su interés o que consideró relevantes para su formación. En este sentido, la identificación de lo que el escultor ha captado en su taccuino podría resultar de gran importancia para aproximarnos a la manera en que se desarrolló el aprendizaje en Roma de los jóvenes artistas españoles. Asimismo, también podría proporcionar ciertos datos que nos conducirían a los personajes que habrían permitido el acceso a espacios que no estaban abiertos al público en los que algunos pensionados tuvieron ocasión de copiar obras sugeridas por la Real Academia de Bellas Artes de San Fernando de Madrid o que, en ocasiones, habrían elegido según su proprio gusto.

Palabras clave: Antonio Primo, Giovan Battista Ponfreni, Roma, Academias, Carlo Maratta, Corrado Giaquinto, Escultura, Real Academia de Bellas Artes de San Fernando, Felipe de Castro, Francisco Preciado de la Vega.

ABstRact: During his sojourn in Rome Antonio Primo used a sketchbook in which he drew everything that would capture his attention and interest (1761-1764).The identification of what we find in his notebook is of great relevance, in order to understand how young artists used to train in Rome during the first stage of their careers; this also allows to make the acquaintance of some important figures who let artists enter non-public spaces, where they had the opportunity to study and copy works of art.

Keywords: Antonio Primo, Giovan Battista Ponfreni, Rome, Academies, Carlo Maratta, Corrado Giaquinto, Sculpture, Real Academia de Bellas Artes de San Fernando, Felipe de Castro, Francisco Preciado de la Vega. 


\section{"Omne tulit punctum, qui miscuit utile dulci" \\ Horacio, verso 343 de Ars poetica ${ }^{1}$}

El cuaderno en que queda recogida al menos una parte del aprendizaje en Italia del escultor jienense Antonio Primo (Andújar, 1735-Madrid, 1798) $)^{2}$, utilizado con bastante probabilidad entre 1761 y $1764^{3}$ y conservado en el Meadows Museum, Southern Methodist University de Dallas (72.06) desde 1972, ha pasado inadvertido a los especialistas y únicamente en los últimos años ha suscitado un cierto interés que ha cristalizado en algunas publicaciones que se ocupan de él ${ }^{4}$.

${ }^{1}$ Este verso 343 de Ars poetica de Horacio es citado por Francisco Preciado de la Vega, tutor de los pensionados enviados a Roma por la Real Academia de Bellas Artes de San Fernando de Madrid, en su obra Arcadia pictórica en sueño, alegoría ó poema prosaico sobre la teoría y la práctica de la pintura escrita por Parrasio Tebano, pastor arcade de Roma, Madrid, 1789, p. 323.

${ }^{2}$ El presente artículo se ha elaborado en el marco del proyecto ACAF/ART III Cartografías analíticas, críticas y selectivas del entorno visual y monumental del área mediterránea en la edad moderna (HAR 2012-32680) financiado por el Ministerio de Economía y Competitividad.

${ }^{3}$ En el cuaderno de Antonio Primo existen algunas referencias cronológicas que nos sirven para acotar el tiempo durante el que habría podido utilizarlo. La primera de ellas se encuentra en la página inicial del mismo en la que, además de identificarse como Antonio Primo, pensionado en Roma, indica el año 1761 y alude a un personaje llamado Isaac Vol (...) Mengod, del que por el momento no tenemos información alguna, aunque podría tratarse de un contacto de cierta importancia durante su estancia en Italia. El año 1761 se reitera en la página 14 en donde ha escrito lacónicamente "61", mientras que en una página suelta, probablemente arrancada y quizá la última del cuaderno, ha anotado que concluyó el cuaderno el 15 de marzo de 1764.

${ }^{4}$ Archivo de la Real Academia de Bellas Artes de San Fernando (en adelante ARABSF), 1-49-1, Pensionados. Antonio Primo gozó de escasa fortuna tras su regreso a España una vez concluida la estancia en Roma puesto que no consiguió abrirse un hueco en el panorama artístico de nuestro país. Una de las últimas noticias que tenemos de él es una carta que envió a la Real Academia de Bellas Artes de San Fernando el 29 de diciembre de 1787 en la que cuenta que, aunque ésta le había concedido una pensión de 4 reales al año para formarse en Roma, sin embargo no había realizado todos los pagos estipulados. De este modo, Antonio Primo
En ellas queda patente que estamos ante un instrumento de gran utilidad para conocer la manera en que se desarrollaba la formación de los jóvenes artistas enviados a Roma por la Real Academia de Bellas Artes de San Fernando de Madrid ${ }^{5}$. Por esta razón, proseguir con la labor de identificación de las imágenes del cuaderno de Primo y profundizar en el análisis de aquellas cuya fuente de inspiración ya ha sido desvelada significa avanzar, no sólo en el estudio de los criterios que determinaron la elección las obras y en la manera en que se copiaban, sino también en el conocimiento de las relaciones o contactos de los que habrían podido gozar los pensionados y que, con bastante probabilidad, habrían posibilitado su acceso a ciertos espacios, algunos de ellos de naturaleza más bien privada, en los que estudiar obras relevantes para su formación.

GIOVAN BATTISTA PONFRENI, UN POSIBLE CONTACTO PARA EL ACCESO AL PALACIO CORSINI

En la página 7 de su cuaderno, Primo ha llevado a cabo a lápiz negro una ejercitación veloz y espontánea del retrato de Faustina Maratta, hija del célebre pintor Carlo, obra también interpretada como

consideraba, tal y como manifiesta en dicha carta, que cuando regresase a España habría cobrado el dinero que se le debía. Se trata de un documento que refleja la precariedad en que se encontraba, su delicada situación económica ante la imposibilidad de desarrollar una carrera exitosa que le obligaba a pedir a la Real Academia madrileña el dinero que aún le debía.

${ }^{5}$ Para una mayor información sobre las características físicas del cuaderno, sobre las vicisitudes que rodearon la estancia de Antonio Primo en Italia y acerca de lo sucedido una vez que regresó a España se recomienda la consulta de los siguientes textos: C. AGÜERO, "Antonio Primo. Cuaderno italiano", en J. M. MATILLA (coord.), Roma en el bolsillo. Cuadernos de dibujo y aprendizaje artístico en el siglo XVIII. Catálogo de la exposición, Madrid, Museo Nacional del Prado, 15 de octubre de 2013-19 de enero de 2014, Madrid, 2013, pp. 96-109; R. GALLEGO, "El estudio de la formación de los pensionados en Roma entre 1758 y 1766: el taccuino de Antonio Primo", en E. MARCH y C. NARVÁEZ (eds.), Vidas de artistas y otras narrativas biográficas, Barcelona, 2013, pp. 349-374. 


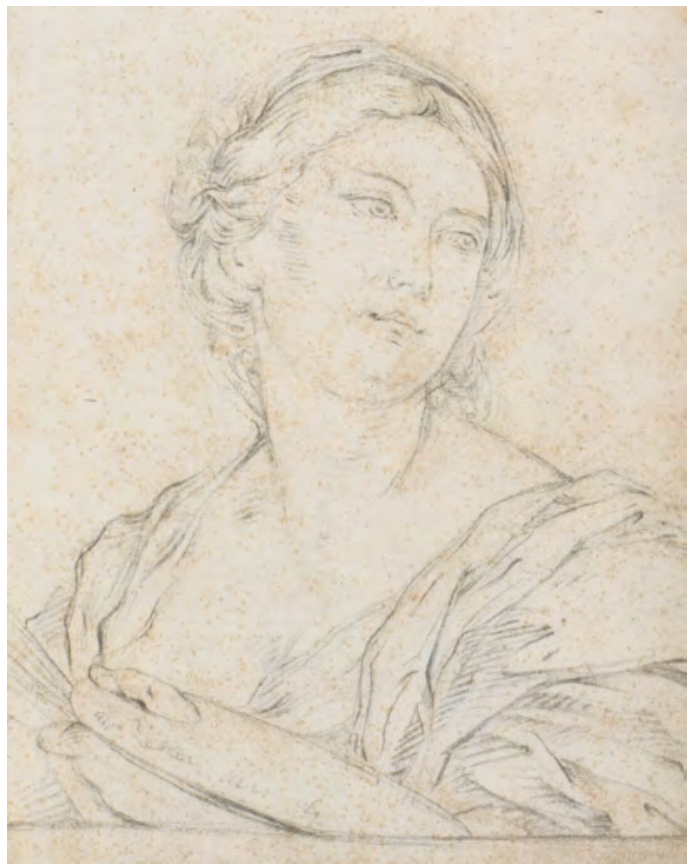

- Fig. 1. Antonio Primo. Copia del autorretrato de Faustina Maratti. Meadows Museum, Southern Methodist University, Dallas.

una alegoría de la Pintura ${ }^{6}$ y conservada en la Galleria Nazionale d'Arte Antica in Palazzo Corsini ${ }^{7}$ que se encuentra en la calle de la Lungara de Roma ${ }^{8}$ (Fig. 1). En vir-

${ }^{6}$ Para la numeración de las páginas del cuaderno de Antonio Primo hemos recurrido al export proporcionado por el Meadows Museum, Southern Methodist University de Dallas.

${ }^{7}$ La ejercitación a partir del cuadro de Faustina Maratti ha sido analizada en R. GALLEGO, Op. cit., pp. 367-369.

${ }^{8}$ E. BORSELLINO, Lungara: storia di un cantiere, Fassano, 1988; ÍDEM, Palazzo Corsini, Roma, 1995. La familia Corsini, de origen florentino, decidió buscar una sede estable en Roma en 1730, año en que Lorenzo Corsini se convirtió en papa con el nombre de Clemente XII. Tras haber alquilado el palacio Pamphili en la plaza Navona y haber cedido el que poseían en la plaza Fiammetta a la familia Bussi se interesaron por el palacio del duque Nicola Riario, ubicado en la via della Lungara y puesto a la venta precisamente en 1730 . Tras un largo periodo de reflexión, la familia Corsini adquirió el edificio de la Lungara mediante un acto de compraventa que se llevó a cabo el 27 de julio de 1736 y fue entonces cuando se inició un dilatado proceso de restauración del edificio del que se ocupó el arquitecto toscano Ferdinando Fuga. El cardenal Neri Maria Corsini tuvo un especial interés en mejorar la galería donde se encontraba parte de su colección de cuadros dispuestos en cinco tud del modo en que ha trabajado no hay demasiadas dudas de que estuvo en el interior del palacio, de la misma manera que también en él se habría ejercitado Mariano Salvador Maella (Valencia, 1739-Madrid, 1819), pensionado de la academia madrileña junto a Antonio Primo, quien dibujó en su cuaderno ${ }^{9}$ la Mater Dolorosa ${ }^{10}$ e hizo un boceto y un óleo de la Salomé con la cabeza de san Juan Bautista ${ }^{11}$, ambas de Guido Reni $^{12}$.

La presencia de al menos Primo y Maella en el palacio Corsini que, a diferencia del Museo Capitolino, abierto al público desde 1734 por voluntad de Clemente XII, no era un espacio en el que los artistas podían entrar libremente, nos obliga a preguntarnos quién podría haber sido el contacto que les facilitó el acceso. Quizá Francisco Preciado de la Vega (Sevilla, 1713-Roma, 1789), tutor de los pensionados, hubiese recomendado a los jóvenes la ejercitación a partir de algunas de las obras que se encontraban en el palacio romano para lo que habría contado con la colaboración de Giovan Battista Ponfreni (Roma, 1714-Roma, 1795) quien habría procurado el acceso al interior del edificio de la Lungara. De hecho, la colaboración entre Ponfreni y Preciado de la Vega es más que probable en virtud a la amistad existente

salas que constituían su apartamento en el piano nobile del palacio.

En el interior del palacio existía también una rica biblioteca que fue instituida y abierta oficialmente al público en el año 1754 por el cardenal Neri Corsini, quien estipuló que pudiese ser visitada en las horas en que permanecían cerrados otros lugares de lectura pública en Roma.

${ }^{9}$ Museo Nacional del Prado, Madrid. 1758-1790.

${ }^{10}$ Galleria Nazionale d'Arte Antica in Palazzo Corsini, Roma. 1617-1618.

${ }^{11}$ Ibídem. 1638-1639.

12 VV. AA., Cuadernos italianos en el Museo del Prado. Francisco de Goya, José del Castillo y Mariano Salvador Maella. Catálogo de la exposición, (en línea), 2013, consultado el 20 de julio de 2015, p. 531. https://www. museodelprado.es/exposiciones/info/en-el-museo/roma-en-el-bolsillo-cuadernos-de-dibujo-y-aprendizajeasrtistico-en-el-siglo-xviii(catalogo-online/ 
entre ambos, una cuestión sobre la que los especialistas no han indagado aún ${ }^{13}$.

Antes de explicar cuáles fueron los vínculos existentes entre Ponfreni y el tutor de los pensionados españoles, sería oportuno indicar en qué consistió la relación del primero con los Corsini ${ }^{14}$. En el archivo florentino de esta familia se conserva un documento que refleja la venta de 52 cuadros en 1763 por parte de Ponfreni a los Corsini, la mayoría de ellos retratos peritados por el pintor Giacomo Zoboli, destacado alumno de Carlo Maratta ${ }^{15}$. Las obras fueron pagadas de una

13 A. CESAREO, "In possa per Giovanni Battista Ponfreni...: su di un ritratto di Agostino Penna all'Accademia di San Luca a Roma", Studi romani, $\mathrm{n}^{\mathrm{o}}$ 1/2, 55, 2007 (2009), pp. 237-24; G. B. FIDANZA, "Storia minima di Giovanni Battista Ponfreni (1714-1795)", Annali della Pontificia Insigne Accademia di Belle Arti e Lettere dei Virtuosi al Pantheon, $\mathrm{n}^{\mathrm{o}}$ 11, 2011, pp. 273-298. Son muy pocos aún los datos que tenemos sobre Giovan Battista Ponfreni, del que se conserva un autorretrato en la Accademia di San Luca realizado cuando contaba con 76 años y en el que se refiere a sí mismo como pintor. Es probable que Ponfreni fuese muy activo en el panorama artístico romano de la segunda mitad del siglo XVIII dedicándose especialmente al comercio de obras de arte, lo que le puso en contacto con algunos relevantes personajes como Luigi Crespi. De su faceta de pintor se conservan muy pocas obras y uno de los escasos datos que tenemos, puesto que él mismo lo cuenta en una carta al conde Niccolò Soderini, es que se formó con Marco Benefial.

${ }^{14}$ E. BASSI (ed.), I quaderni di viaggio di Antonio Canova, Firenze, 1959, p. 30. Una buena prueba de la celebridad de Giovan Battista Ponfreni en la Roma del momento nos la da Antonio Canova que pasó dos años de formación en esta ciudad (1779-1781) durante los cuales tuvo tiempo para visitarlo: "Dopo desermi levato decci vari piccoli servizi poi andiedi dal Signore Giam Battista Ponfreni Pittore che sta in piaza Barbarini mi Fece dimostrazione di sincera Amicizia".

${ }^{15}$ Archivio Corsini de Florencia (en adelante ACF), Giustificazioni dei pagamenti dal signor Paolo Bindi maestro di casa dell'Eccellentissima casa Corsini da gennaio a giugno, filza 76, 1763; ÍDEM, stanza 15, campata 6, palco 4, inserto 49. Inventario dei quadri del cardinale Andrea Corsini a Roma. En el mencionado inventario se especifican algunos de los cuadros que fueron vendidos por Ponfreni a la familia Corsini, concretamente se habla de un original flamenco de dos palmos en el que se puede ver a una anciana, un cuadro del cardenal Filomarino de Domenichino, una obra de manera un tanto peculiar ya que Ponfreni no recibió una suma de dinero, sino una asignación mensual vitalicia que cobraba regularmente en el palacio Corsini, un procedimiento de pago que habla de una intensa y continuada relación entre el romano y la familia florentina y que garantiza su presencia, al menos una vez al mes, en el palacio de la Lungara.

Sobre la existencia de un importante vínculo entre Ponfreni y Preciado de la Vega albergamos muy pocas dudas ya que se conserva una larga carta fechada el 20 de octubre de 1765 que ha sido recogida por Giovanni Gaetano Bottari en la que el sevillano expresa sus opiniones sobre la pintura española a petición de Ponfreni, lo que denota que éste tenía en alta consideración los criterios del tutor de los pensionados de la Real Academia madrileña y que existía un intercambio de ideas y de criterios sobre cuestiones artísticas ${ }^{16}$. Asimismo, se puede hablar de una proximidad física entre ambos; Preciado de la Vega residió durante toda su estancia en Roma, con excepción de los primeros años en que vivió en la parroquia de Sant'Andrea delle Fratte, en una casa sita en la plaza Barberini adscrita a la parroquia de Santa Susanna ${ }^{17}$, primero en compañía del escul-

Leonardo, quizá una copia, que representaba una mujer y un retrato de Lorenzo de Medici que se atribuye a Andrea del Sarto.

${ }^{16} \mathrm{G}$. G. BOTTARI, Raccolta di lettere sulla pittura, scultura ed architettura, Bologna, 1980, pp. 211-236.

${ }^{17}$ Aunque la parroquia de Santa Susanna no es una de las que mayor densidad de artistas presenta a la luz del estudio de los estados de ánimas que se conservan en el Archivio Storico del Vicariato de Roma (en adelante ASVR), allí vivió un discreto número de figuras relevantes del panorama artístico romano algunas de las cuales habrían podido tener una cierta importancia en la formación de los pensionados españoles. En ella residieron Johann Joachim Winckelmann, Filippo della Valle, quien vivió en la calle de San Nicola Tolentino de manera permanente junto a toda su familia y en donde tenía su taller, el también escultor Agostino Penna y el pintor Vincenzo Stringelli. Filippo della Valle y Agostino Penna debieron ejercer una enorme influencia en los jóvenes escultores que gravitaban en torno a Preciado de la Vega. De hecho, en el caso de Della Valle da buena 
tor Francisco Vergara (Alcudia, 1713-Roma, 1761), que más tarde se trasladó a la parte de la via Felice perteneciente a la parroquia de San Nicola in Arcione ${ }^{18}$, y posteriormente permaneció en esta misma casa con su esposa la pintora Caterina Cherubini y con la hermana de esta ${ }^{19}$. Muy cerca de Preciado de

prueba de esta relación el matrimonio de Juan Adán y de Gabriel Durán, ambos pensionados extraordinarios de la Real Academia de Bellas Artes de San Fernando, con las hijas del escultor Violante y Petronilla respectivamente. Dichos matrimonios tuvieron lugar en marzo de 1776 en la parroquia de Santa Susanna (ASVR, Santa Susanna, liber matrimoniorum, 3, 1774-1810).

${ }^{18}$ ASVR, San Nicola in Arcione, stati delle anime, 1760: “Felice/ Nel vicolo de PP. Capuccini/ Altra rimessa/ I e II Piano/ C Giuliano Saturni 36/ C Francesco Bergara 36/ C Teresa Saturni Mog 25/ Domenico fig 1/ C Maria Mangossi Bay a 26/ C Andrea ser". Ibídem, 1761: "Felice/ Nel vicolo d. PP. Capuccini/ I e II Piano del Maculaori/ C Giuliano Saturni 37/ C Francesco Vergara 38/ Teresa Saturni 28/ Domenico 2/ Anna Mํ Fig 1/ C Candida Bucci ser 31/ C Giuseppe Verrachi ser 23".

${ }^{19}$ Preciado de la Vega se ocupó hasta el final de sus días de la tutela de los jóvenes artistas que se formaban en Roma desde 1758, año en que la Real Academia de Bellas Artes de San Fernando instituyó de forma oficial las pensiones concedidas en un primer momento mediante concurso y que posteriormente se adjudicaron extraordinariamente en virtud a los méritos alegados por quienes deseaban ir a Italia o incluso por artistas que se encontraban ya allí, y casi siempre gracias a la vinculación de los jóvenes a artistas que formaban parte de la órbita de la academia madrileña. La proximidad de Preciado de la Vega a sus pupilos se refleja en su testamento del 12 de febrero de 1781 al que se adjuntó un documento fechado el 21 de marzo de 1782 (Archivio di Stato de Roma, (en adelante ASR), Offici della Curia del Cardinale, officio 32, Clementi) y en el que todos los testigos fueron jóvenes que estudiaron bajo la tutela del sevillano: Gabriel Durán, José Guerra, Agustín Navarro, Carlos Espinosa, Francisco Ramos, Santiago Folch y Pascual Cortés.

Preciado de la Vega realizó algunas matizaciones a su testamento en un documento que se fecha el 18 de noviembre de 1788 (ASR, Trenta Notai Capitolini, ufficio 26, Milanesi) del que fueron testigos Giacomo della Visitazione y Vittorio della Santissima Annunziata, ambos agustinos descalzos del convento de San Nicola Tolentino, Buenaventura Salesa, un joven pintor que se formaba en Roma, y los romanos Benedetto Antonio Allegrini y Giuseppe Messi. Otro aspecto que queda patente en el testamento es que la vida del director de los pensionados en Roma se desarrolló de manera más bien modesta, de forma muy diferente a la de los directores de la Vega vivió Ponfreni ya que residía habitualmente en el convento de los capuchinos, dato que conocemos gracias al testamento llevado a cabo en la notaría de Meglioriucci, uno de los Treinta Notarios Capitolinos, $\mathrm{y}$ en el que prestaron testimonio siete frailes del mencionado convento ${ }^{20}$. Además, es posible que Ponfreni hubiese sido un contacto extraordinario para Preciado de la Vega a la hora de resolver la compleja cuestión del alojamiento de los jóvenes españoles en Roma que, a diferencia de los franceses que vivían todos juntos en el palacio Mancini ubicado en la via del Corso, no disponían de un espacio común ${ }^{21}$. El pintor romano podría haber mediado para que se diese cobijo a algunos de ellos, especialmente a los pensionados, en estructuras conventuales que se encontraban en el ámbito de la parroquia de Santa Susanna ${ }^{22}$. De este modo, el tutor de los pen-

la Académie de France en el palacio Mancini, una figura a la que Preciado se refirió en diversas ocasiones a la hora de reclamar unas condiciones mejores ante la Real Academia de Bellas Artes de San Fernando. De hecho, poco antes de morir poseía muy pocos bienes que prácticamente consistían en algunos cuadros suyos que dejó a sus sobrinos que vivían en Sevilla a quienes también legó la suma de 10 escudos, una cantidad realmente muy pequeña.

${ }^{20}$ IASR, Trenta Notai Capitolini, ufficio 12, Meglioriucci, enero de 1795. Giovanni Battista Ponfreni hizo testamento el 21 de enero de 1792 y en el precisaba que vivía en el convento de los capuchinos. Al no tener hijos dejó sus propiedades a Alessandro Tomasi del que no se proporciona noticia alguna y sobre el que tan sólo sabemos que era un personaje de su absoluta confianza.

${ }^{21}$ M. GUERCI, Palazzo Mancini, Roma, 2011.

${ }^{22}$ ASVR, Santa Susanna, stati delle anime, 1761: "Strada Salara/ 534 monastero / di S. Basilio/ sacerdoti no 8/ laici no 3/ S. Pietro Conca chie.co 23/ Domenico Alvarez/ Pictore 23". Quizá la presencia de Domingo Álvarez Enciso, pensionado de la Real Academia de Bellas Artes de San Fernando desde 1758, en el pequeño convento de San Basilio durante el año 1761 y con bastante probabilidad también en 1762, podría haber sido posible gracias a la intercesión de Ponfreni. Además, habría que precisar que la permanencia en el convento de San Basilio coincide con algunos problemas de comportamiento que se refieren en la junta ordinaria de la Real Academia de Bellas Artes de San Fernando de 27 de julio de 1762 en que se señala que el pintor "andaba embobado con las mujeres", lo que ocasionó que se le 
sionados podía seguir muy de cerca el desarrollo de su formación en Roma informando regularmente a la Real Academia madrileña de cualquier incidencia o irregularidad en el comportamiento de los jóvenes.

Asimismo, Ponfreni, además de facilitar el acceso al palacio Corsini, habría podido interceder para que los artistas españoles en periodo de formación trabajasen en el interior de las Logias Vaticanas en las que dibujaron la mayoría de ellos ${ }^{23}$. En este sentido, es necesario recordar que, si bien es cierto que Ponfreni fue nombrado director de la Fábrica Pontificia de Mosaicos en 1776, el mismo año en que se le admitió como académico de mérito en la Accademia di San Luca, la relación con este ámbito habría podido comenzar mucho antes ${ }^{24}$.

retirase la pensión. Es probable, por tanto, que Preciado de la Vega con el apoyo de Ponfreni decidiese que Álvarez Enciso residiese en el mencionado convento con el fin de poder controlar mejor el desarrollo de su formación en Roma (ARABSF, Juntas particulares, ordinarias, generales y públicas, 1757-1769, Signatura 3/82, junta ordinaria, 27 de julio de 1762).

${ }^{23}$ E. BASSI (ed.), Op. cit., pp. 34-35, 37. Antonio Canova es un buen ejemplo de la intercesión de Ponfreni para que los jóvenes artistas pudiesen trabajar en el Vaticano, ya que le consiguió la oportuna licencia.

${ }^{24}$ Algunos pensionados españoles dibujaron en sus cuadernos los mosaicos del Vaticano. Por ejemplo, Antonio Primo en la página 90 del taccuino del museo de Dallas ha bosquejado tímidamente, captando únicamente la silueta de las figuras, la escena de San Pedro bautizando a los santos Proceso y Martiniano que también suscitó el interés de José del Castillo, quien pergeñó esta escena en la página 25 de su segundo Cuaderno italiano, y de Maella tal y como se puede ver en la página 121 de su Cuaderno italiano. En cualquier caso, no es de extrañar que hubiese sido Preciado de la Vega quien indicase a los pensionados la conveniencia de ejercitarse a partir de dicho mosaico ya que, según apunta en la página 180 de su texto Arcadia pictórica en sueño, nutría una enorme admiración por Pietro Paolo Cristofari: "Suelen aplicarse algunos a pintores de mosaico, pero no por eso salen con el honor que desean, pues para pintar de aquel modo es necesaria también la inteligencia de tintas, y una buena práctica en usarlas, como la tuvo el caballero Cristofari, que en el Vaticano de Roma copió el cuadro de Santa Petronila por el original del Guercino, logrando el crédito y la fama, que merecía su inteligencia".

\section{UNA VISTA DE LA IGLESIA DE SAN} PAOLO FUORI LE MURA

Tan sólo en dos ocasiones, en las páginas 13 y 40 de su cuaderno, Antonio Primo se detiene en la captación de un paisaje quizá porque no era un objeto de ejercitación prescrito por la Real Academia madrileña a sus pensionados. En el punto 28 de las Instrucciones para el director y los pensionados del Rey en Roma de pintura y escultura que vio la luz en octubre de 1758, ideado esencialmente por Felipe de Castro (Noia, La Coruña, 1711-Madrid, 1775) a partir de su propia experiencia formativa en Roma, se recomienda a los jóvenes artistas que lleven consigo "un libro de memoria" en el que tomar apuntes de obras que se hallen en templos, palacios, jardines y fuentes, así como de adornos de singular interés existentes en ellos aunque nada se dice sobre la importancia del paisaje. Sin embargo, en el palacio Mancini sí debió representar un objeto de gran interés, casi una forma de recreo habitualmente practicada por los artistas que se formaban en la Académie de France, de hecho los pensionados galos realizaron múltiples excursiones por los alrededores de Roma así como breves viajes a los Castelli Romani en donde se detenían en la captación de paisajes, algunos de ellos protagonizados por bucólicas ruinas.

El dibujo a sanguina de la página $13 \mathrm{del}$ cuaderno de Antonio Primo ha sido identificado por el propio escultor, quien en raras ocasiones especifica lo que capta y cuando lo hace es bastante frecuente que recurra al francés. En este caso ha anotado su ejercitación lacónicamente en la base de la página utilizando un término italiano: "veduta de san pablo" (Fig. 2). Se trata de una vista de la iglesia de San Paolo fuori le Mura, una de las cuatro iglesias patriarcales de Roma ubicada en la via Ostiense muy cerca de la pirámide Cestia y del hospital femenino de San Michele, un espacio que, por aquel entonces, estaba bastante alejado del centro de la ciudad y que no aparece en ningún otro cuaderno de pensionados españoles de los que tenemos 


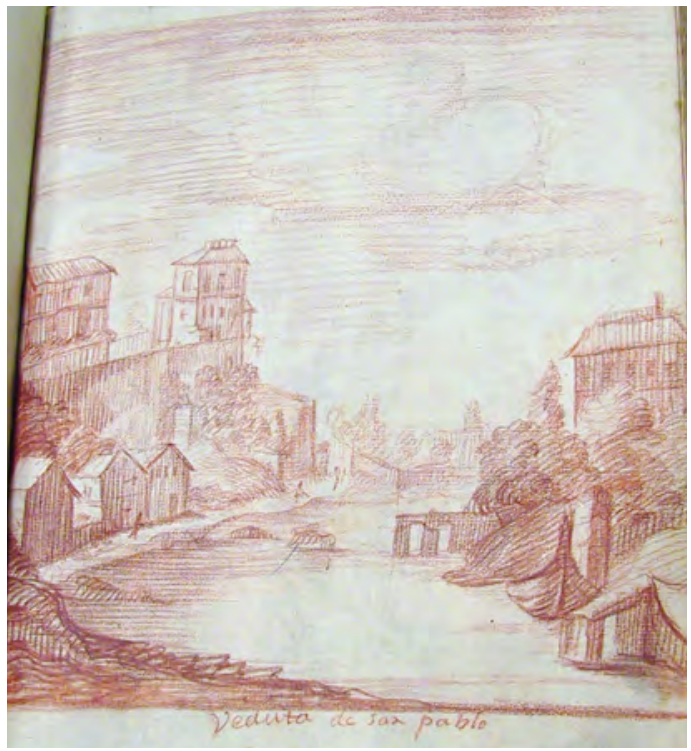

- Fig. 2. Antonio Primo. Vista de la iglesia de San Paolo fuori le Mura, Roma. Meadows Museum, Southern Methodist University, Dallas.

conocimiento hasta el momento ${ }^{25}$. Se puede considerar una elección un tanto insólita, probablemente fruto de una excursión que le habría llevado a este punto de los alrededores de Roma, un ejercicio veloz en el que no parece manifestar especial interés por el edificio resuelto de forma superficial, un recuerdo de su paso por esta parte de la ciudad.

\section{LA PRUDENCIA Y LA INOCENCIA DE CARLO MARATTA EN LA IGLE- SIA DE SAN MARCO}

Antes de pergeñar en su cuaderno una imagen de la Religión tomando como referencia la $\mathrm{Fe}$ de Simone Giorgini (p. 47) de la iglesia de San Ignacio, de captar la estatua de Roma sedente o Roma Cesi (p. 48) en el Museo Capitolino, las alegorías de la Fortaleza, de la Fe y de la Pobreza (pp. 49-51) de Domenichino que están en el centro del ábside de la nave central de Sant'Andrea della Valle ${ }^{26}$ para pro-

${ }^{25}$ F. TITI, Studio di pittura, scoltura et architettura nelle chiese di Roma (1674-1763), en B. CONTARDI y S. ROMANO (eds.), Firenze, 1987, p. 38. "La chiesa di S. Paolo sudetto che è fuori di Roma più d'un miglio nella Via Ostiense, di smisurata grandezza ebbe la sua prima fondatione da Constantino il Magno".

${ }^{26}$ R. GALLEGO, Op. cit., pp. 361-363. seguir más tarde con una ejercitación a partir de Raquel (p. 52), obra de Corrado Giaquinto en la capilla Ruffo de la iglesia de San Lorenzo in Damaso ${ }^{27}$, Antonio Primo pasó por la iglesia de San Marco y bosquejó con lápiz negro las figuras de la Prudencia y de la Inocencia (pp. 45 y 46). Aunque no sería de extrañar que todas estas ejercitaciones se hubiesen realizado en una jornada de trabajo, también podrían haber sido programadas para llevarse a cabo en diversas sesiones teniendo en cuenta su pertenencia a una misma zona de la ciudad, dada la evidente proximidad de los espacios en que se encuentran las obras a las que nos hemos referido. Asimismo, todas ellas responden a un análogo criterio formal, puesto que se trata de figuras alegóricas femeninas aisladas y casi siempre sedentes que podrían haber constituido una reflexión para el escultor a la hora de confrontarse con el tratamiento de los pliegues, cuestión determinante en la formación de los jóvenes artistas especialmente en el ámbito académico.

Una vez en el interior de la iglesia de San Marco, no muy lejos de la Scuola del Nudo ubicada en la plaza del Campidoglio y a donde Antonio Primo debía asistir con regularidad, tal como prescribía la Real Academia madrileña, se habría detenido en el baptisterio situado a la izquierda de la puerta y allí le habrían llamado la atención los frescos de la Prudencia y de la Inocencia que se atribuyen a Carlo Maratta, aunque puede ser que ya los conociese y que fuese a San Marco expresamente para copiarlos ${ }^{28}$. De entre las dos figuras femeninas habría determinado comenzar por la Inocencia que es la que

${ }^{27}$ Ibídem, pp. 359-361.

${ }^{28}$ Estas dos imágenes, que se completan con una representación de la Virgen con el Niño Jesús y dos ángeles que portan sendas filacterias, se encuentran bastante bien iluminadas por su proximidad a la puerta y gracias a la presencia de un vano en el centro de la pared del baptisterio. No será esta la única intervención de Carlo Maratta en la iglesia de San Marco puesto que, por encargo de Ottavio Specchi, realizó también la que se considera una de sus obras más relevantes, La adoración de los reyes Magos, en la que el artista no esconde su admiración por el trabajo de Giovanni Lanfranco. 


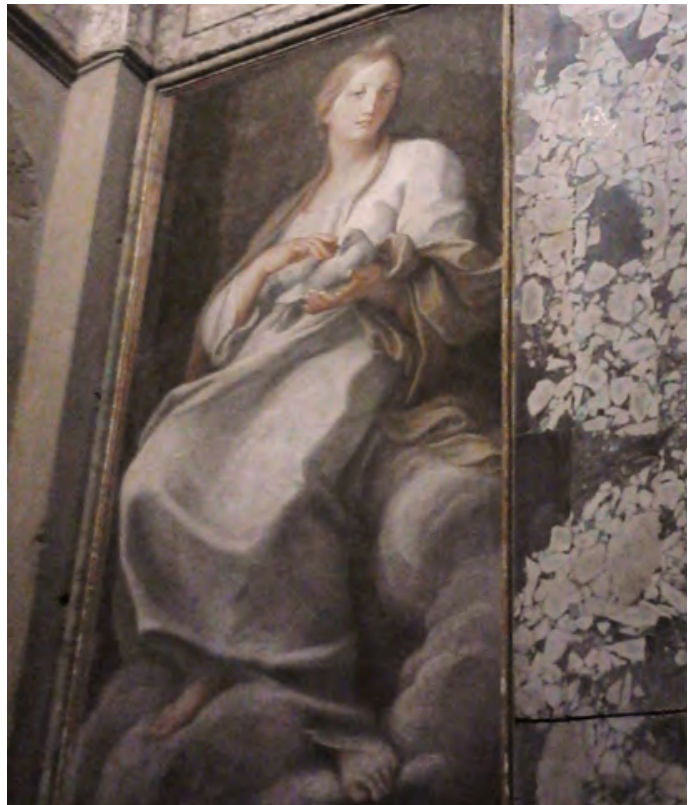

- Fig. 3. Carlo Maratta. La Inocencia. Iglesia de San Marco, Roma. Foto de la autora

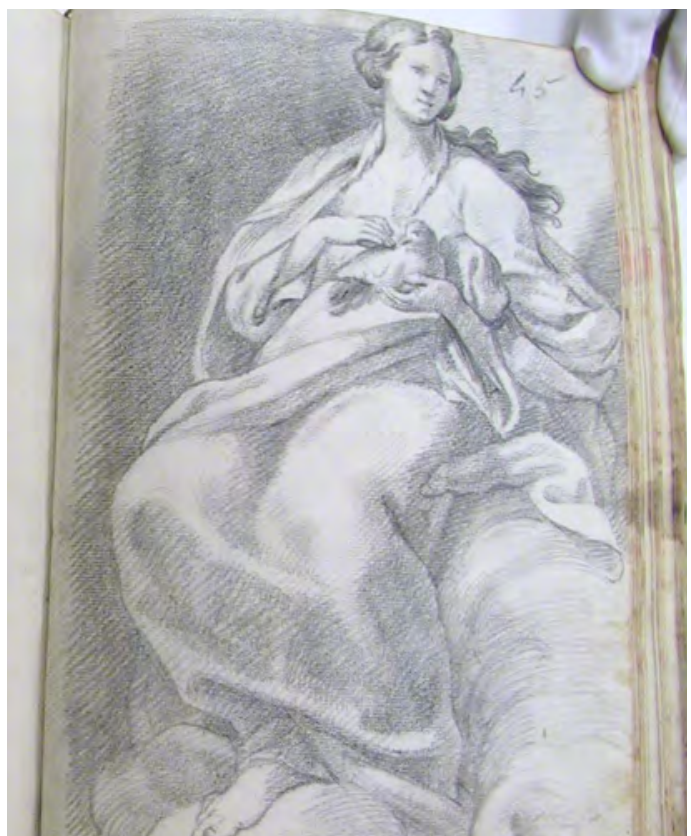

- Fig. 4. Antonio Primo. Copia de La Inocencia a partir del fresco de Carlo Maratta. Iglesia de San Marco, Roma. Meadows Museum, Southern Methodist University, Dallas.

se encuentra frente a la puerta y, por tanto, la que está mejor iluminada (Figs. 3 y 4 ).

Además, con respecto a la Prudencia, Primo copió la Inocencia con mayor rigor, captando con precisión los pliegues de las vestiduras de la figura alegórica y las nubes

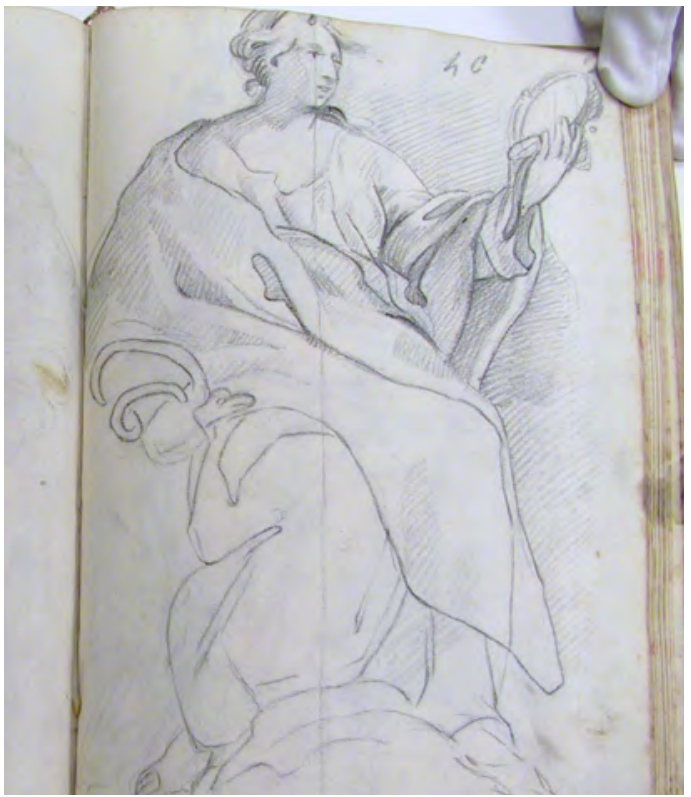

- Fig. 5. Antonio Primo. Copia de la Prudencia a partir del fresco de Carlo Maratta. Iglesia de San Marco, Roma. Meadows Museum, Southern Methodist University, Dallas.

en que apoya sus pies, sin embargo, resolvió rápidamente la Prudencia (Fig. 5).

Estas dos figuras alegóricas no sólo atrajeron la atención de Antonio Primo sino también de otros artistas que en la mayor parte de los casos se formaron en la Académie de France como Edmé Bouchardon, que dibujó ambas alegorías ${ }^{29}$ con extraordinaria precisión trabajando de manera muy parecida a como lo hizo Primo en la figura de la Inocencia. También fueron objeto del interés de Jean-Robert Ango, personalidad aún muy poco conocida y en gran medida vinculada a la Académie de France que se ganaba la vida en Roma como copista, quien ha captado la Prudencia y la Inocencia de forma rápida ${ }^{30}$, y de Annicet Charles Gabriel Lemonier, pensionado francés que dibujó ambas figuras -la Prudencia en dos ocasiones- en su cuaderno ${ }^{31}$.

Los bocetos de la Prudencia y de la Inocencia en el taccuino de Antonio Primo nos

${ }^{29}$ Musée du Louvre. Département des Arts Graphiques, Paris. 1723-1730.

${ }^{30}$ Ibídem. 1765-1773.

${ }^{31}$ Ibídem. 1774-1784, fols. 84, 85, 86. 
permiten hacer una doble reflexión. La primera de ellas es que el escultor andaluz se debía encontrar muy próximo al ambiente francés, ya que dichas figuras de Maratta no aparecen en otros cuadernos de pensionados españoles que han llegado hasta nosotros, un aspecto que entra en consonancia con algunas anotaciones que éste hace en lengua francesa en diversas partes de su cuaderno.

La segunda es que la elección de estas figuras alegóricas, tanto en el caso de Antonio Primo como en el de los pensionados franceses a los que nos hemos referido, debió estar condicionada, al menos parcialmente, por la comodidad a la hora de ser copiadas. Las imágenes de la Prudencia y de la Inocencia se solían colocar en las pechinas de las cúpulas de muchas iglesias romanas $\mathrm{o}$, en cualquier caso, en lugares elevados, lo que dificultaba su observación. Sin embargo, en la iglesia de San Marco están prácticamente a la altura de los ojos y se encuentran adecuadamente iluminadas lo que facilita ostensiblemente el trabajo. Asimismo, el hecho de que el autor de las mismas fuese Carlo Maratta las hacía aún más interesantes puesto que era un referente en el mundo académico y un ejemplo a seguir para los jóvenes en periodo formativo prescrito en el reglamento de la Academia madrileña $^{32}$ y sugerido con frecuencia por Preciado de la Vega, tal y como demuestra en su texto Arcadia pictorica ${ }^{33}$.

${ }^{32}$ ARABSF, Instrucciones para el director y los pensionados del rey en Roma, Signatura 50-5/1.

${ }^{33}$ F. PRECIADO DE LA VEGA, Op. cit., pp. 87-88 y 236. "En este defecto incurrió varias veces Camillo Rusconi en sus bellas estatuas, bien que fue singular por otra parte en buena forma de los pliegues, y en el bello efecto del todo de los paños, habiendose esmerado en imitar el gusto de Carlos Marati; y el uno en sus estatuas, y el otro en sus pinturas os podran servir de regla para imitar su buen gusto y el estilo de plegar, por más que alguno los tache de afectación".

"Carlos Marati puso particular estudio en sus pliegues, y aunque se tachen de afectados, no dexan detener un carácter bello, noble y digno de imitarse, habiéndose esmerado en copiar muchas de las mejores figuras de Rafael, y aun de introducirlas en algunas de sus obras".
UNA INTERPRETACIÓN DE LA FE DE SIMONE GIORGINI EN LA IGLESIA DE SAN IGNACIO

Dentro del conjunto de ejercitaciones de figuras alegóricas femeninas del cuaderno de Antonio Primo se halla, como ya hemos apuntado, el boceto ejecutado a lápiz negro de la página 47. Nos encontramos, muy probablemente, ante una copia de la escultura de la $\mathrm{Fe}$ ubicada en el espacio que está a la izquierda del coro de la iglesia de San Ignacio, obra de Simone Giorgini o Giorgi, un escultor del que tenemos muy pocas noticias y del que se desconocen incluso datos tan esenciales como las fechas y los lugares de su nacimiento y de su muerte aunque se sabe que estuvo activo en Roma entre 1677 y 1712. Dicha escultura forma parte de un conjunto integrado por la Esperanza, la Caridad y la Religión que con bastante probabilidad fue encargado en 1683 a Antonio Raggi, brillante alumno de Gian Lorenzo Bernini, quien no pudo trabajar en este proyecto por motivos de salud falleciendo tres años después de que le fuese encargada dicha comisión ${ }^{34}$. Sin embargo, es muy posible, o por lo menos así lo cree el historiador Robert Engass, que Raggi hubiese dejado algunos dibujos que sirvieron de guía a los diversos artistas que se ocuparon de la ejecución de las obras, de entre los que sobresalía Camillo Rusconi, seguidor del trabajo de Carlo Maratta, con el que Raggi habría entrado en contacto gracias a su amistad con el alumno predilecto de éste, Giuseppe Bartolomeo Chiari.

Antonio Primo copió la imagen de la $\mathrm{Fe}$ introduciendo ligeras variaciones como la postura de la mano que sostiene el cáliz y añadió la cruz convirtiendo de este modo la alegoría de la $\mathrm{Fe}$ en una representación de la Religión, tal y como anota en la página anterior de su cuaderno en la que se puede leer la palabra Religione. Asimismo, hay un aspecto que deja poco espacio a la duda de que la fuente de inspiración para el dibujo de esta página haya sido la obra de Giorgini: los tra-

${ }^{34}$ R. ENGASS, "Rusconi and Raggi in Sant'Ignazio", The Burlington Magazine, $\mathrm{n}^{\mathrm{o}}$ 116, 1974, pp. 258-262. 


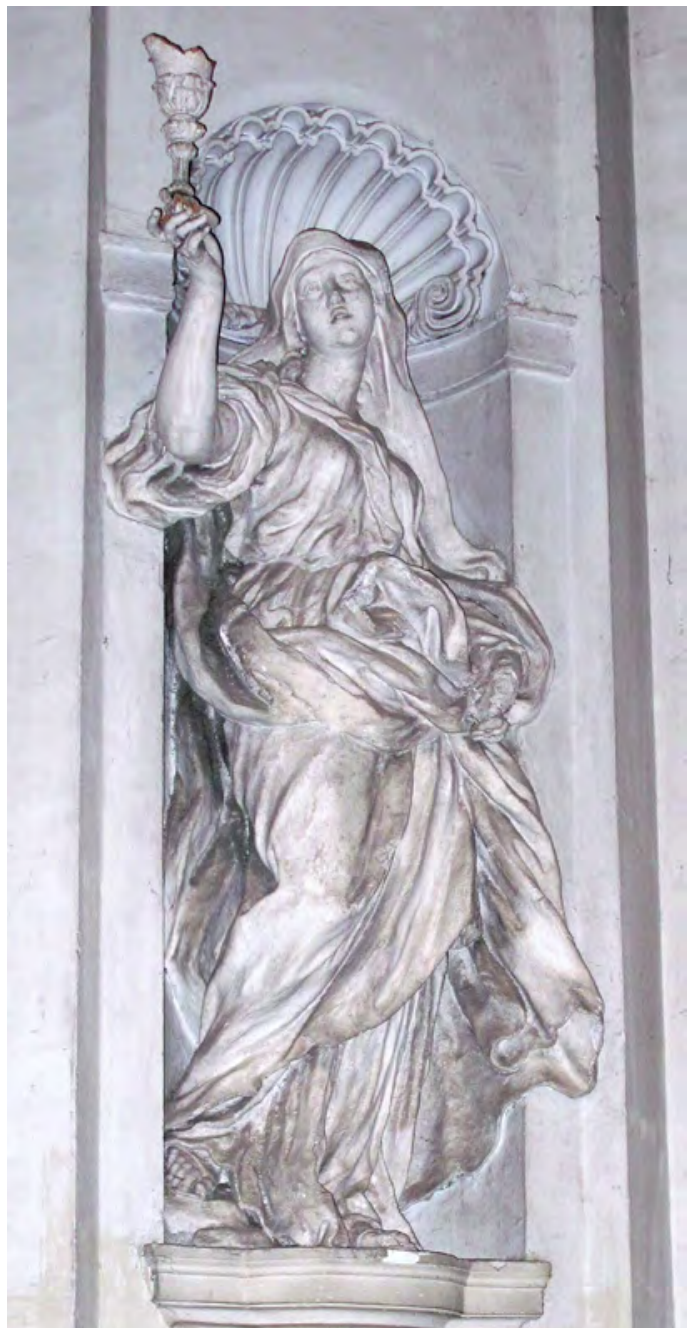

- Fig. 6. Simone Giorgini o Giorgi. La Fe. Iglesia de San Ignacio, Roma. Foto de la autora.

zos de la parte superior del boceto hacen una clara referencia a la hornacina avenerada en que se ubica la escultura en el interior de la iglesia de San Ignacio (Figs. 6 y 7).

Antonio Primo habría podido saber que esta obra, antes de ser ejecutada por Giorgini, fue comisionada a Antonio Raggi, uno de los artistas que la Real Academia de Bellas Artes de San Fernando recomendaba fervientemente para la formación de los escultores en el punto 26 del reglamento de 1758 e incluso podría ser conocedor de que se realizó a partir de un dibujo del discípulo de Bernini. Tampoco debiéramos excluir la posibilidad de que circulase en ambientes académicos algún boceto de la figura de la

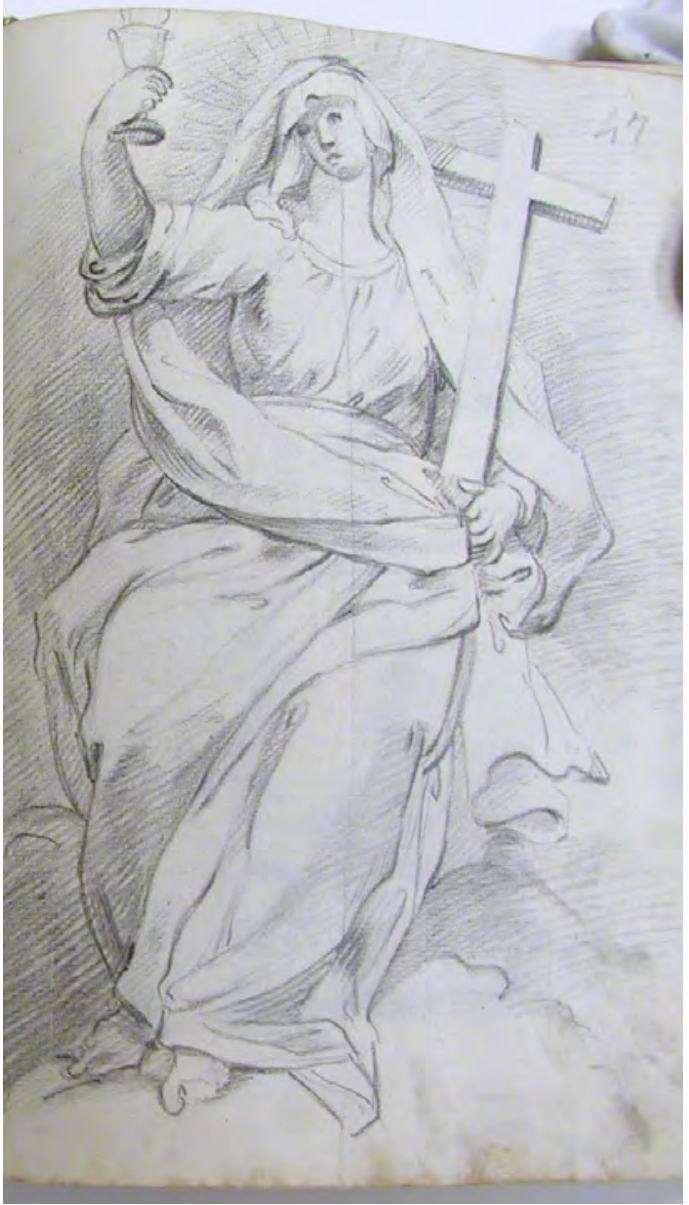

- Fig. 7. Antonio Primo. La Religión, a partir de la escultura de la Fe de Simone Giorgini o Giorgi. Iglesia de San Ignacio, Roma. Meadows Museum, Southern Methodist University, Dallas.

$\mathrm{Fe}$ de Raggi y que algunas de las modificaciones realizadas por Primo en su taccuino puedan corresponder a la concepción inicial del artista para esta obra.

En cualquier caso, este dibujo representó para Antonio Primo un buen pretexto para analizar una imagen que generalmente se encontraba en las pechinas de las cúpulas o en lugares elevados. Aunque aquí la figura de la $F e$ no se sitúa a la altura de los ojos, como la Inocencia y la Prudencia de la iglesia de San Marco, sino en una posición ligeramente más elevada, la ejercitación a partir de ella debía ser más bien cómoda y tenía lugar en un ambiente íntimo lo que consintió a Primo trabajar desahogadamente. 


\section{UNA EJERCITACIÓN EN EL MUSEO CAPITOLINO: LA ESCULTURA DE ROMA CESI}

En varias páginas de su cuaderno el escultor jienense ha realizado dibujos de obras que se encontraban en el Museo Capitolino ubicado en la plaza del Campidoglio, en el mismo ámbito en que se hallaba la Scuola del $\mathrm{Nudo}^{35}$. Una de ellas es la imagen de la escultura colosal de Roma (p. 48) que pergeñó a lápiz negro desde un lateral, y no frontalmente como cabría esperar, puesto que la obra se encontraba, y se encuentra aún hoy, en una hornacina. Quizá Antonio Primo dibujó la escultura desde un lado para poder captar mejor los pliegues de las vestiduras y por tanto se podría sospechar que se hubiese confrontado con la obra clásica como si de un estudio de panneggio se tratase (Fig. 8) ${ }^{36}$.

${ }^{35}$ L. BARROERO, "I primi anni della scuola del Nudo in Campidoglio", en Benedetto XIV e le arti del disegno". Actas del Convegno Internazionale di Studi di Storia dell'Arte, Bologna, 28-30 de noviembre de 1994, Roma, 1998, pp. 367-384. La Scuola del Nudo se encontraba muy cerca del Museo Capitolino, es decir, en la plaza del Campidoglio, en un espacio que en la actualidad es la sede de la biblioteca de la Avvocatura del Ayuntamiento de Roma. Era un ambiente de forma oval modificado por Giovan Paolo Pannini cuando se instituyó la estructura académica en 1754 con la voluntad de ser libre y gratuita para que los jóvenes artistas de cualquier nacionalidad pudiesen ejercitarse en la captación anatómica a partir de un modelo vivo. La intervención de Pannini consistió, entre otras cosas, en una ampliación de las dimensiones de las tres ventanas, una de las cuales fue transformada en puerta de ingreso a la sala, lo que permitía una mayor iluminación en un espacio en el que la luz era un elemento de vital importancia para el desarrollo del trabajo.

En una de las múltiples ocasiones en que Antonio Primo debió asistir a la Scuola del Nudo decidió copiar en la página 81 de su cuaderno la personificación del Nilo, que se encuentra aún hoy en la plaza del Campidoglio. La pieza, proveniente de las termas de Constantino, fue dispuesta en el lado izquierdo de la escalera a doble rampa que conducía al Aula Senatoria. El escultor ha trabajado de manera rápida y concentrándose en los contornos en una ejercitación en que ha conseguido captar adecuadamente la potencia matérica de la figura masculina recostada y apoyada sobre una esfinge.

${ }^{36}$ También el pensionado José del Castillo dibujó la imagen del Roma Cesi desde un lateral en la página

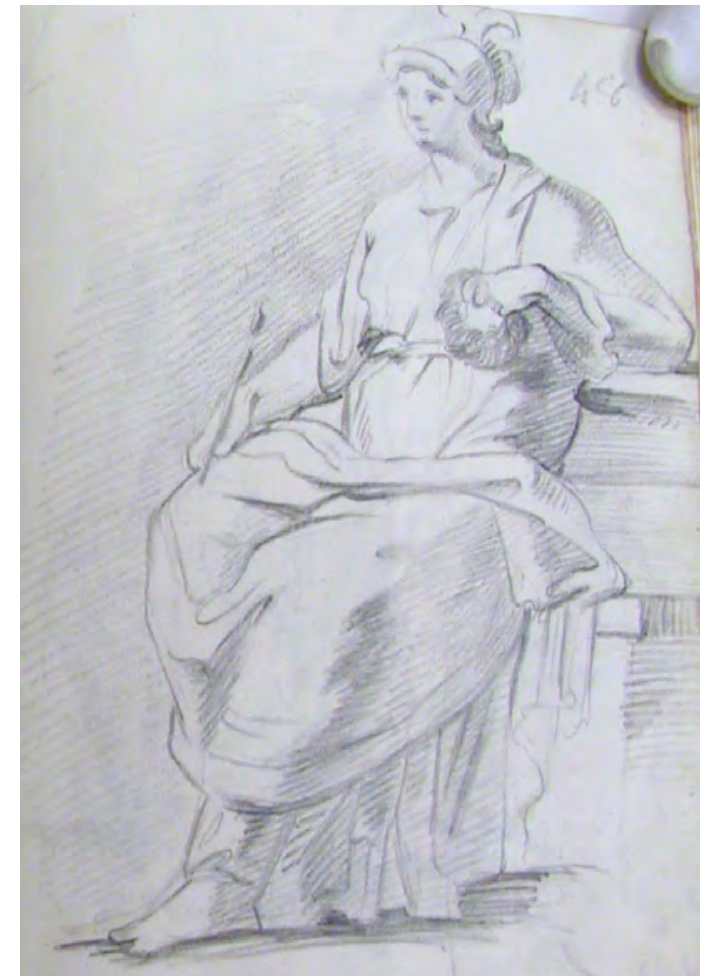

- Fig. 8. Antonio Primo. Roma Cesi a partir de la escultura de los Musei Capitolini. Meadows Museum, Southern Methodist University, Dallas.

La escultura colosal de Roma, llevada a cabo en la época de Adriano y perteneciente a la colección Cesi, fue adquirida en 1719 por Clemente XI y colocada en 1720 en el segundo pórtico del patio del Palacio de los Conservadores, en el que tenía su sede el Museo Capitolino. En origen formaba parte del denominado Grupo Cesi integrado por Dacia, Roma y dos prisioneros y debió suscitar un cierto interés en los artistas que asistían a la Scuola del Nudo, que a menudo complementaban los trabajos a partir de modelos vivos con las ejercitaciones en las que se copiaban las esculturas del Museo Capitolino. Asimismo, no debiéramos olvidar que en los años en que Primo estudiaba en Roma la mencionada escultura podría haber experimentado una cierta revitalización, puesto que los Conservadores presentaron a Clemente XIII un proyecto de cuatro tapices destinados a

152 de su tercer cuaderno (Museo Nacional del Prado, Madrid). 


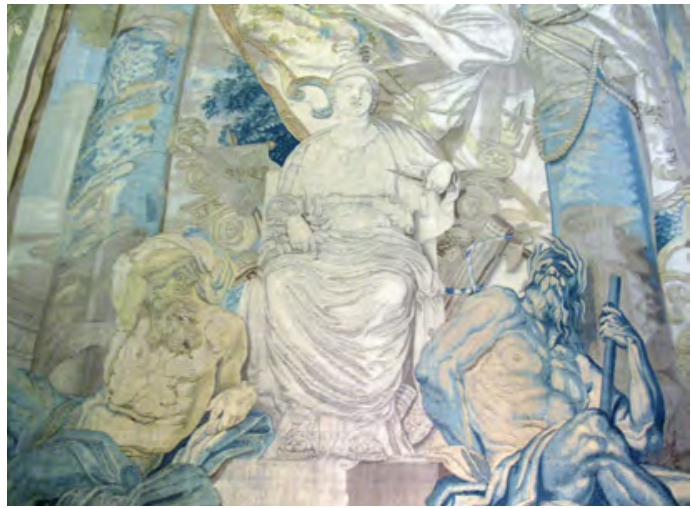

- Fig. 9. Domenico Corvi. La diosa Roma en el trono. Musei Capitolini, Roma. Sala degli Arazzi. Foto de la autora.

decorar las paredes de la sala del Trono de su palacio. Se determinó que dicho proyecto fuese llevado a cabo por Pietro Ferloni, director de la Tapicería Pontificia, y por Domenico Corvi, miembro activo de la Accademia di San Luca, director de la Scuola del Nudo en varias ocasiones y poseedor de una de las academias privadas más célebres de Roma. Corvi trabajó entre 1764 y 1766 en los modelos para los cartones que giraban en torno a la Romanidad y a la Historia Antigua, uno de los cuales era Roma sedente, para la que recurrió como inspiración a la Roma Cesi y a la personificación de los ríos Tíber y Aniene de la Fuente de los Ríos en la plaza Navona, obra de Gian Lorenzo Bernini (Fig. 9) ${ }^{37}$.

\section{EL RELIEVE DE ANTONINO PIO ASISTIENDO A UN CONGIARIUM CONSERVADO EN EL PALACIO AL- BANI}

Antonio Primo ha pergeñado en su cuaderno el relieve fechado en el II d. C. (p. 54) en que Antonino Pio asiste a un congiarium acompañado por la Abundancia y por la Dea Roma. En un primer momento esta obra se conservaba en los jardines Cesi, en las in-

${ }^{37}$ A. CASCIARDI, "Roma Cesi: la storia e la fortuna", en L. NORCI CAGIANO DE AZEVEDO, Roma triumphans!, l'attualità dell'antico nella Francia del Settecento, Actas del Convenio internacional de estudios, Roma, Centro di studi italo-francesi, 9 - 11 marzo de 2006, Roma, 2007, pp. 299-309. mediaciones del Vaticano, y posteriormente fue llevado a la villa que Alessandro Albani hizo construir a Carlo Marchionni en la Salaria, concluida antes de 1758 . El relieve se colocó junto a uno de los vanos de ingreso en la gran sala que está en el primer piso del edificio, así lo constata un dibujo realizado por Pierre-Adrien Pâris a mediados de los años setenta del siglo XVIII. La disposición de muchos de los relieves, entre los que se encontraba el que aquí nos ocupa, y de esculturas antiguas en paredes divididas y separadas por paneles, tal y como se hace en la gran sala del primer piso del palacio Albani, recordaba a los gabinetes y studioli ${ }^{38}$. El palacio Albani fue convertido por su poseedor en el espacio que habría de albergar su importante colección de esculturas y relieves antiguos comenzada por su tío Clemente XI y que él continuó gracias a la colaboración y a los consejos de Francesco Bianconi y de Winckelmann, quienes no sólo le recomendaron la adquisición de ciertas piezas, sino que también fueron sus bibliotecarios (Figs. 10 y 11).

Además del boceto de Antonio Primo, existen diversos dibujos de esta pieza, el primero de ellos es el que Giovanni Antonio Dosi o Dosio realizó a mediados del siglo XVI y en el que ha eludido el podio en que se sitúan los personajes así como la silla curul del emperador. El relieve de Antonino Pio aparece también en el cuadro Paisaje al alba con la cella de un templo en ruinas del pintor francés Jean Lemaire ${ }^{39}$, conocido como Le Gros Lemaire. En él podemos ver en la base derecha de la pintura el relieve fracturado en su ángulo superior izquierdo que se encuentra en medio de un bucólico paisaje. Asimismo, la escena de Antonino Pio asistiendo a un congiarium interesó también a Nicolas Poussin que dibujó el relieve quizá

${ }^{38}$ A. ALLROGGEN-BEDEL, "La villa Albani: criteri di scelta e disposizione delle antichità", en Collezionismo e ideologia. Mecenati, artisti e teorici dal classicismo al neoclassico, Roma, 1991, pp. 206-207, nota 19.

${ }^{39}$ El mencionado cuadro, que habría podido ser realizado a comienzos del siglo XVII, se conserva actualmente en una colección privada londinense. 


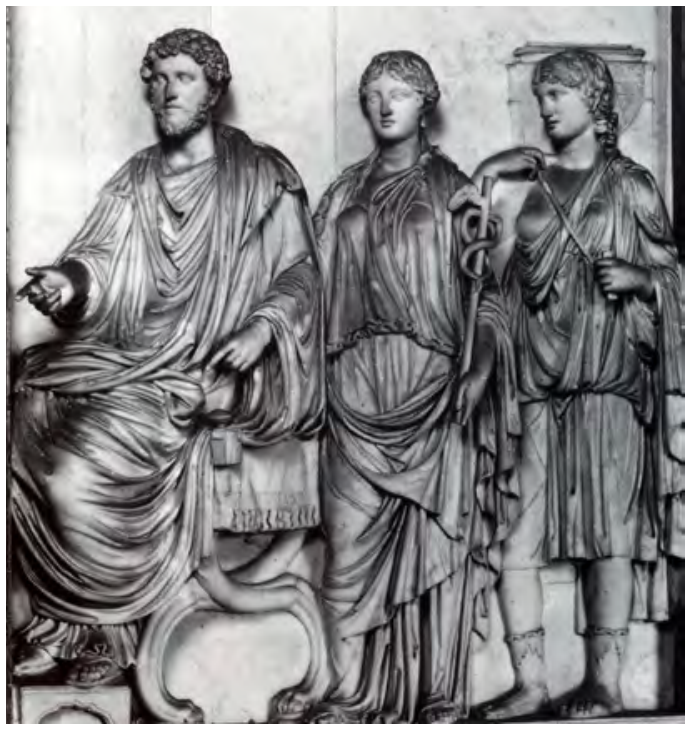

- Fig. 10. Antonino Pio asistiendo a un "congiarium". Collezione Albani, Roma. Foto de la autora.

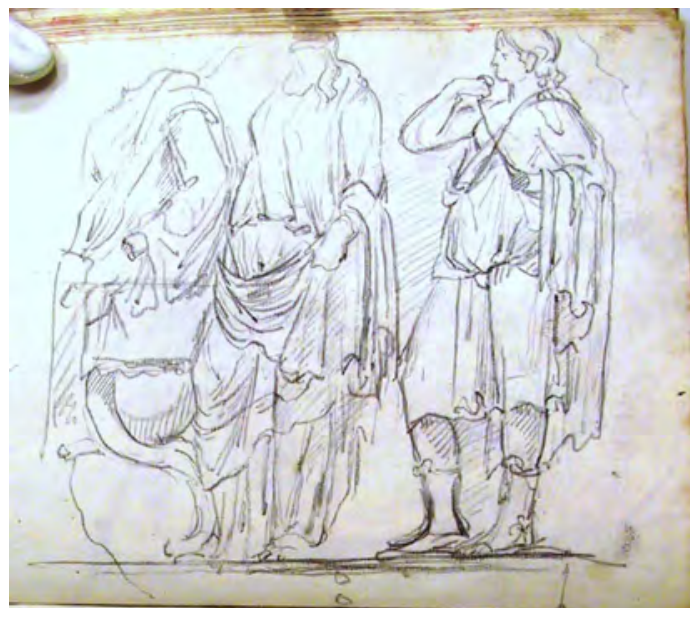

- Fig. 11. Antonio Primo. Antonino Pio asistiendo a un "congiarium" a partir de la escultura del palacio Albani. Meadows Museum, Southern Methodist University, Dallas.

observando la escultura ${ }^{40}$, aunque habría podido conocer el dibujo de esta pieza que formaba parte del Museo Cartaceo de Cassiano del Pozzo ${ }^{41}$. Éste, encargado en 1615 por Del Pozzo, amigo y mecenas de Poussin, estaba integrado por 7000 acuarelas y dibujos de los que varios centenares son copias de piezas clásicas. La sospecha de que Poussin

\footnotetext{
${ }^{40}$ El dibujo de Poussin se conserva en el Musée Condé de Chantilly.

${ }^{41}$ Dicha parte del Museo Cartaceo se halla en la Royal Library, en el Castillo de Windsor.
}

trabajase en ocasiones copiando dibujos pertenecientes al Museo Cartaceo es manifestada por Walter Friedländer quien cree que el francés prefirió, en muchos casos, las imágenes del Museo Cartaceo y los vaciados de Cassiano del Pozzo a los propios originales. Este compendio de dibujos estaba en 1761 en la colección del cardenal Alessandro Albani, que se la compró a su tío Clemente XI quien, a su vez, lo adquirió de los herederos de Del Pozzo. El Museo Cartaceo se desmembró en julio de 1762, momento en que una parte muy significativa del mismo que incluía la copia de la escultura de Antonino Pio, fue comprada por Jorge III de Inglaterra quien la llevó a su biblioteca de Buckingham House.

La fidelidad con que Antonio Primo ha copiado la escultura da licencia para imaginar que lo hubiese hecho contemplando el original, aunque no debiéramos subestimar la coincidencia que se advierte entre el dibujo del escultor andaluz y la copia que de esta pieza se incluía en el Museo Cartaceo, puesto que en la base derecha de ambas imágenes se puede ver unos clavos que servirían de sujeción de la misma a una peana. Además, como hemos apuntado anteriormente, en el año 1761 el Museo Cartaceo estaba ya en manos del cardenal Albani y quizá Primo podría haber visto la lámina correspondiente a la escultura de mármol completando su estudio con la observación del relieve.

El ambiente del palacio Albani debía ser muy estimulante para un joven artista puesto que era frecuentado por personalidades de la talla de Winckelmann o de Anton Raphael Mengs que trabajaba en el palacio Albani pintando el fresco de El Parnaso (1761). Quizá allí Primo habría tenido ocasión de entablar conversaciones con este último, al que seguramente ya conocía por su vinculación a la Real Academia de Bellas Artes de San Fernando, y no es de extrañar que Mengs hubiese podido orientar algunas de sus elecciones e incidir en el desarrollo de su formación en la ciudad eterna, incluso habría podido ser precisamente él quien le introdujese en el palacio Albani. 


\section{UN POSIBLE DIBUJO A PARTIR DE UN TRABAJO DE FELIPE DE CASTRO}

Antonio Primo ha pergeñado un dibujo a lápiz negro en la página 77 de su cuaderno en el que ha marcado con insistencia los contornos del mismo. Se trata de la figura de un obispo que porta la palma del martirio y que se ha colocado en el centro de lo que podríamos definir una secuencia de tres imágenes muy parecidas entre si, ejercitaciones que suponen variantes de sujetos similares. Estaríamos, por tanto, ante una forma de trabajar análoga a la de las alegorías femeninas de las que nos hemos ocupado anteriormente. Incluso es probable que estos tres dibujos hayan salido de una misma fuente de inspiración, aunque tan sólo en la que analizamos en este apartado se lee en la base de la página la palabra "Castro". Se podría tratar de una mención al escultor Felipe de Castro, quien desde Madrid supervisaba la formación de los pensionados ordinarios y extraordinarios enviados por la Real Academia de Bellas Artes de San Fernando y que, como ya hemos apuntado, había estudiado en Roma entre los años 1733 y 1745 junto a Preciado de la Vega. No es de extrañar que Castro hubiese legado al sevillano algunas de las ejercitaciones, dibujos o quizá modelos de terracotta realizados durante su estancia en Italia que debieron ser de gran utilidad para Preciado quien, presumiblemente, regentaba una academia privada en su casa de la plaza Barberini en la que habría puesto a disposición de los jóvenes artistas el material que poseía y a partir del cual se habrían podido ejercitar ${ }^{42}$. De este modo, el boceto realizado por Antonio Primo podría ser, como él mismo sugiere, la copia de un dibujo o de un pequeño modelo de terracotta que Felipe de Castro habría podido dejar en la casa de Preciado de la Vega (Fig. 12).

${ }^{42}$ C. DE LA CRUZ ALCAÑIZ y J. GARCÍA SÁNCHEZ, "L'Accademia romana di Francisco Preciado de la Vega in piazza Barberini e gli artisti spagnoli del Settecento", Bollettino d'arte, no 7, 94, 2009, pp. 91-102; ÍDEM, “Piazza Barberini: a Spanish Artists' District in Eighteenth-Century Rome", The Burlington Magazine, $\mathrm{n}^{\circ}$ 152, 2010, pp. 665-670.

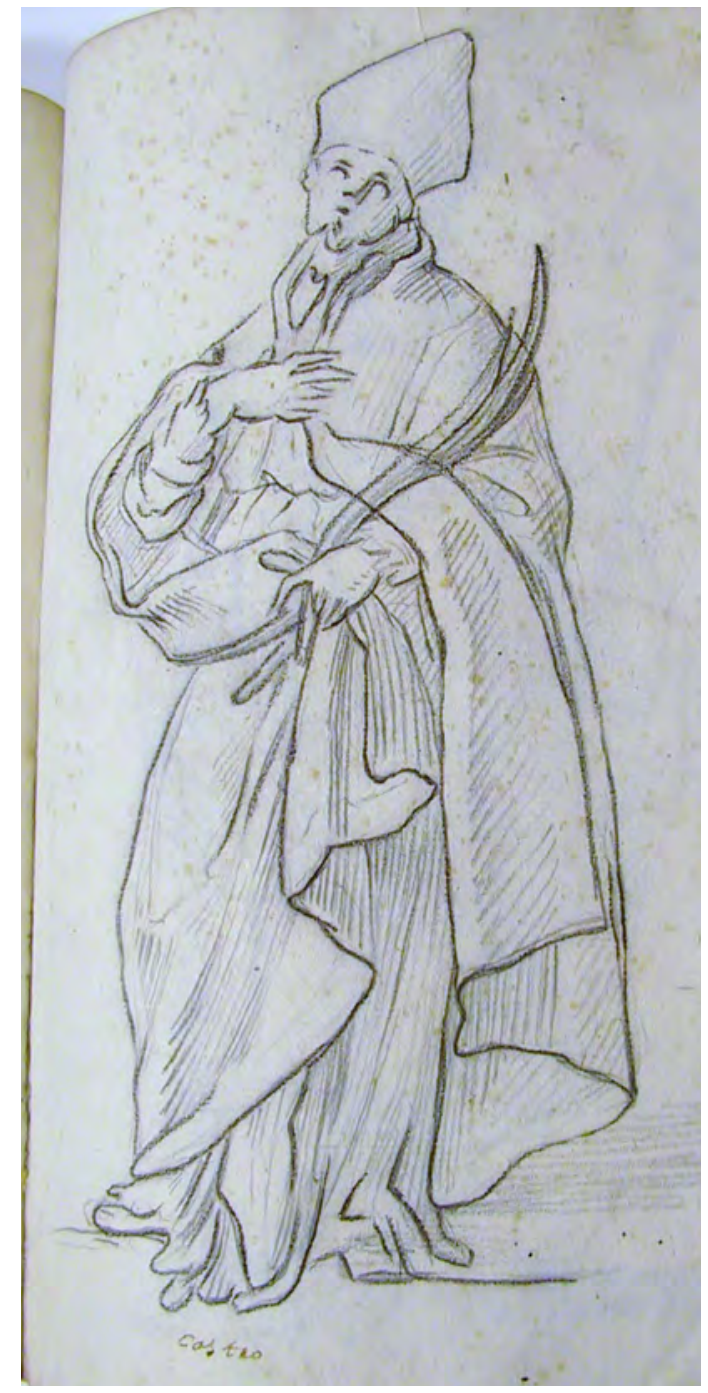

- Fig. 12. Antonio Primo. Obispo mártir. Meadows Museum, Southern Methodist University, Dallas.

La figura copiada por el escultor andaluz en su cuaderno presenta analogías con algunas de las esculturas del colonnato de la plaza de San Pedro del Vaticano, en concreto con la figura del obispo San Giuliano de Antonio Alignini o de Antonio Galbano. Quizá Castro habría podido inspirarse en ella durante su asistencia a la academia privada de Sebastiano Conca, fundada en torno a 1712 y regentada por él hasta 1752, año en que abandonó Roma ${ }^{43}$. De hecho, aunque el tipo

${ }^{43}$ R. GALLEGO, "De los Carracci a Sebastiano Conca: la Sala Grande del palacio Farnese como espacio para la formación de los jóvenes artistas", ActalArtis, nº 2, 2014, pp. 25-49. 
de enseñanza impartida en las academias privadas es una cuestión muy nebulosa sobre la que existen muy pocas noticias, gracias a Pietro Leone Bombelli tenemos constancia de que en la regentada por Conca existía un libro con los dibujos de todas las esculturas del colonnato de la basílica de San Pedro que podían utilizar los alumnos ${ }^{44}$. De este modo, los jóvenes podían detenerse en la observación de las obras sin necesidad de copiarlas in situ lo que era mucho más incómodo y habrían podido llevar a cabo ejercitaciones más precisas que las que obtendrían trabajando a partir de los originales.

\section{CONCLUSIONES}

Las nuevas imágenes identificadas en el cuaderno de Antonio Primo, así como las consideraciones realizadas en torno a algunas ejercitaciones cuya fuente de inspiración ya se conocía, corroboran la idea de que el escultor debió programar muchas de ellas con cierta antelación. Buena prueba de ello son los bocetos de las alegorías femeninas, que demuestran que las eligió con un criterio bien preciso, es decir, el de trabajar sobre la cuestión del tratamiento de los pliegues a partir de este tipo de figuras casi siempre sedentes, seleccionando las que se encontraban en la mayoría de los

${ }^{44} \mathrm{~V}$. MARTELLI, Le statue berniniane del colonnato di San Pietro, Roma, 1987, p. 287: “Le centoquaranta statue in travertino di santi, e sante della chiesa latina, e greca, che d'ordine del sommo pontefice Alessandro VII, e di altri suoi successori, sono state poste per ornamento sul meraviglioso colonnato della Basilica Vaticana, furono nei tempi passati, come nei nostri, in molto pregio presso gli intendenti, ed anche presso i soggetti del merito più distinto, quali sono stati, tra gl'altri famosi pittori Sebastiano Conca, e Raffaelo Antonio Mengs, nome immortale, che solo basta per rilevarne l'eccellenza. Il primo le aveva tutte disegnate in un gran libro; e il secondo ne disegnò molte da se stesso; e più, se non tutte, ne avrebbe disegnato, se la morte non lo avesse tolto alle belle arti (...). É poi cosa interessante per i professori, e dilettanti del disegno il vedere una serie cosí lunga di statue di santi, e sante, con tanta varietà di azioni, di pannegiamenti, di fisonomie; disegnate con tanta maestria, e perfezione, e quasi tutte sullo stesso gusto, che possono dar materia di molto studio, e da trarne gran profitto". casos en lugares bien visibles y en iglesias muy próximas entre sí ubicadas en el centro de la ciudad. De esa manera han de ser interpretados también los bocetos de los obispos, uno de los cuales se habría llevado a cabo a partir de una ejercitación o modelo de Felipe de Castro que Primo habría podido tener la oportunidad de conocer en la casa de Preciado de la Vega, lugar determinante para todos los pensionados españoles, así como para muchos jóvenes artistas que se formaban en Roma.

Asimismo, la elección por parte de Antonio Primo de obras de Maratta o de Simone Giorgini, autor de una escultura ideada por Antonio Raggi, demuestra su adhesión a los dictámenes académicos, su necesidad de adecuarse a las normas establecidas por la Real Academia de Bellas Artes de San Fernando, quizá con la voluntad de garantizarse un futuro profesional una vez de vuelta a España. Igualmente se advierte una fuerte proximidad a los dictámenes de Francisco Preciado de la Vega que se compendiaron, como fruto de una carrera al frente de los pensionados, en su Arcadia pictórica.

Por otra parte, la presencia de Antonio Primo en el palacio Albani y en el palacio Corsini pone de manifiesto la importancia que los contactos, posiblemente entablados por Francisco Preciado de la Vega, tuvieron a la hora de facilitar su acceso a lugares relevantes para su formación en la ciudad. En este sentido, habría que subrayar la relación del tutor de los pensionados con Ponfreni, una cuestión sobre la que aún es necesario seguir indagando y que podría deparar nuevos datos que explicarían aún mejor la estancia de los jóvenes artistas españoles en Roma.

En definitiva, la profundización en el estudio del taccuino de Antonio Primo nos hace pensar que nos encontramos ante un escultor que condujo su formación en Roma desde un gran respeto de los principios y de los dictámenes académicos ya que en su cuaderno se expresa como un artista escrupuloso en el desarrollo de sus ejercitaciones. Esta 
dimensión de estudiante aplicado contrasta fuertemente con algunos aspectos de su personalidad, que crearon no pocos problemas a Preciado de la Vega y que llevaron a la Real Academia de Bellas Artes de San Fernando a suspenderle la pensión durante un breve periodo ${ }^{45}$. Por último, quisiéramos subrayar las constantes coincidencias en las elecciones de Antonio
Primo con las que hicieron muchos de los pensionnaires que se formaban en la Académie de France. Se puede hablar, por tanto, de concomitancias con el mundo galo más significativas que las existentes en las ejercitaciones presentes en los cuadernos de los pensionados españoles, un aspecto que lo aproxima al ambiente académico francés presente en el territorio romano.

${ }^{45}$ ARABSF, Juntas particulares, ordinarias, generales y públicas, 1757-1769, Signatura 3/82, junta ordinaria, 27 de julio de 1762; R. GALLEGO, El estudio de..., pp. 351-352. Junto a Domingo Álvarez Enciso la Real Academia de Bellas Artes de San Fernando retiró la pensión a Antonio Primo, tal y como se especifica en la junta ordinaria del 27 de julio de 1762, alegando que iba siempre desaliñado y que estaba cargado de deudas. 